\title{
Feminismo em revista: a União Universitária Feminina nas páginas do periódico Jornal das Moças (década de I950)
}

[ Feminism in review: União Universitária Feminina on the pages of the periodical "Jornal das Moças" (the I950s)

\section{Nailda Marinho da Costa ${ }^{\mathrm{I}}$ \\ Priscila Dieguez ${ }^{2}$}

RESUMO $\cdot \mathrm{O}$ artigo analisa notícias publicadas sobre a União Universitária Feminina, escritas por Flora Ferraz Veloso na revista Jornal das Moças na década de I950, buscando perceber de que forma a associação de mulheres universitárias era representada nas páginas do periódico e a relação da articulista com essa entidade. A década de I950 ficou conhecida como o auge dos anos dourados, marcada pelo desenvolvimento e incentivo aos bens de consumo e culturais, que mudariam padrões de comportamento da sociedade brasileira e nela o cenário do ensino superior. PALAVRAS-CHAVE - Associativismo de mulheres; Flora Ferraz Veloso; ensino superior. ABSTRACT - The article analyzes pieces of news published about União Universitária Feminina, written by Flora Ferraz Veloso, on the magazine "Jornal das Moças" during the I950s, trying to know how the university women association was represented on the pages of the periodical, and the relation between the writer and the union. The I950 decade was known as the peak of the golden years, a remarkable time by the development and increasing of consumer and cultural goods, which would change the behavior patterns of the Brazilian society and the higher education scene. KEYWORDS - Women associations; Flora Ferraz Veloso; higher education.

Recebido em 2I de julho de 2020

Aprovado em 7 de julho de $202 I$

COSTA, Nailda Marinho da; DIEGUEZ, Priscila. Feminismo em revista: a União Universitária Feminina nas páginas do periódico Jornal das Moças (década de I950). Revista do Instituto de Estudos Brasileiros, Brasil, n. 79, p. 69-86, ago. 202I.

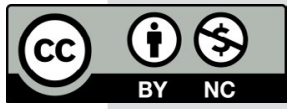

DOI: https://doi.org/Io.II606/issn.23I6-90IX.vIi79p69-86

I Universidade Federal do Estado do Rio de Janeiro (UniRio, Rio de Janeiro, RJ, Brasil).

2 Universidade Federal do Estado do Rio de Janeiro (UniRio, Rio de Janeiro, RJ, Brasil). 
No Brasil dos anos dourados, final da década de I950, uma associação de mulheres universitárias denominada União Universitária Feminina estava presente nas páginas da revista Jornal das Moças nas linhas da articulista Flora Ferraz Veloso. Simbolizando o ativismo feminino, Flora informava às leitoras questões que ocupavam a agenda da associação, como menstruação, saúde da mulher, aposentadoria por tempo de serviço, mercado de trabalho, formação intelectual, mudança no Código Civil.

Entendemos que as fontes utilizadas nesta pesquisa não podem ser consideradas como fidedignas, mas à semelhança de registros de um momento daquilo que se desejava mostrar. Nesse sentido, cabe evidenciar que todo documento só adquire "o estatuto de fonte diante do historiador que, ao formular o seu problema de pesquisa, delimitará aqueles elementos a partir dos quais serão buscadas as respostas às questões levantadas" (SAVIANI, 2005, p. I3).

Nossa fonte primária, a revista Jornal das Moças era um periódico de variedades que publicava propagandas, vendendo produtos de beleza e as grandes novidades de equipamentos para o lar, que visavam facilitar a vida das mulheres enquanto esposas e mães. Suas matérias veiculavam notícias sobre as artistas de rádio, como as cantoras Emilinha Borba, a "Favorita da Marinha" e Marlene, a "Favorita da Aeronáutica", bem como do cinema americano, destaque dado para Elizabeth Taylor e seus conselhos às mulheres e Audrey Hepburn, e os moldes do "vestidinho básico"; contos, notas de agradecimento, anúncios de consultas médicas também desfilavam em suas páginas, englobando até política na época de eleição do presidente Juscelino Kubitschek de Oliveira e o destaque para as possíveis primeiras damas (BATISTA, 20I9).

Destacando no periódico as notícias publicadas sobre a União Universitária Feminina, o presente texto vem estruturado em três seções que se articulam. Em "A revista Jornal das Moças nos anos dourados", caracterizamos o periódico; na segunda seção, "Ações da União Universitária Feminina nas linhas de Flora Ferraz Veloso", definimos os marcos que compõem a instituição e suas ações; em "A advogada Flora Ferraz Veloso: a conquista do diploma ou 'o belo sexo frágil' perante o júri”, seguimos apresentado questões relativas ao ensino superior e nele a presença feminina; a advogada Flora Ferraz Veloso; e as formaturas do curso de direito publicadas nas páginas da revista com destaque para o “belo sexo”. Nas considerações finais, 
destacamos como a União Universitária Feminina se inseria enquanto espaço privilegiado para reflexão de pautas e demandas entre as estudantes e diplomadas no ensino superior, ao final da década de I950.

\section{A revista Jornal das Moças nos anos dourados}

Na visão de Roger Chartier (I992, p. 220), "nenhum texto existe fora do suporte que lhe confere legibilidade; qualquer compreensão de um texto, não importa de que tipo, depende das formas com as quais ele chega até o seu leitor". Refletindo a respeito da revista Jornal das Moças, podemos afirmar tratar-se de uma revista impressa de circulação nacional, publicada semanalmente, um periódico de variedades direcionado especialmente às moças, a começar pelo seu nome.

A primeira edição da revista foi apresentada em 2I de maio de I9I4, sendo a data de sua última publicação ainda não identificada. Podemos apenas afirmar que o último exemplar disponível para consulta na base dados da Hemeroteca da Fundação Biblioteca Nacional é o n. 2.422, datado de I5 de dezembro I96I3.

No primeiro exemplar de I956, "a revista de maior penetração no lar" apresentava-se como de propriedade da Editora Jornal das Moças Ltda., situada na Av. Rio Branco, número 3I, no Rio de Janeiro, uma editora da família Menezes4. Na edição de I3 de setembro de 1956 (n. 2.I52, p. I5), a nota sobre "As Io revistas mais lidas no Brasil" demarca a posição de destaque da revista frente ao mercado editorial, classificação atestada pela McCann Erickson'5, uma agência norte-americana.

Carla Bassanezi Pinsky (20I4, p. 24) caracteriza as leitoras da revista Jornal das Moças como pertencentes a "faixas etárias, graus de escolaridade e poder aquisitivo variados. Porém, a revista passa pelas mãos de toda família; homens e crianças também a leem". Logo, era permitida a toda a família a leitura da revista, devido ao seu caráter "cem por cento familiar", e assim de "maior penetração do lar", garantindo ao leitor em suas edições especiais tratar-se de uma revista que "o Sr. ou a Sra. pode deixar em sua casa porque não há perigo de perversão em nenhuma de suas páginas”.

3 Diego dos Santos Soares e Ursula Rosa da Silva (2013) e Dálete Albuquerque (2014) apontam dezembro de I968. Esta última autora também aponta I965 (ALBUQUERQUE, 20I4). Liana Pereira Borba dos Santos (20II) delimita o fim da publicação em dezembro de I96I enquanto Silvia Sasaki (20II) afirma que encontrou exemplares na Biblioteca Pública Estadual de Florianópolis para consulta até I968.

4 À família Menezes, cabia a chefia da equipe editorial da revista Jornal das Moças, sendo composta de: Agostinho, diretor, a quem era atribuída a fundação da revista, Álvaro Menezes, diretor-gerente até a morte de Agostinho, quando assumiu a diretoria, e Hermínia, esposa de Álvaro, editora do suplemento da revista, o Jornal da Mulher, a partir do ano de I960 (BATISTA, 20I9).

5 A McCann Erickson, que existe até os dias de hoje com o nome de McCann Worldgroup, é uma agência americana especializada em publicidade, que se autoidentifica como a mais criativa e efetiva nessa área de atuação. Possui escritórios em mais de Ioo países ao redor do mundo e inclui em sua rede de trabalho oito ramos de atuação, sendo um deles o de propaganda (tradução livre a partir do site da empresa). 


\section{Jornal das Moças}

\section{A REVISTA CBY POR CQPTO FMMILAR,}

A REVISTA QUE OSR. OU A SRA. PODE DEIXAR

EM SUA CASA PORQUE NAO HA PERIGO DE PRRVEHSHO EM NENHUMA DE SUAS PAGINAS

Figura I - Jornal das Moças, n. 2.235, I7 de abril de I958. Acervo:

Hemeroteca Digital da Fundação Biblioteca Nacional

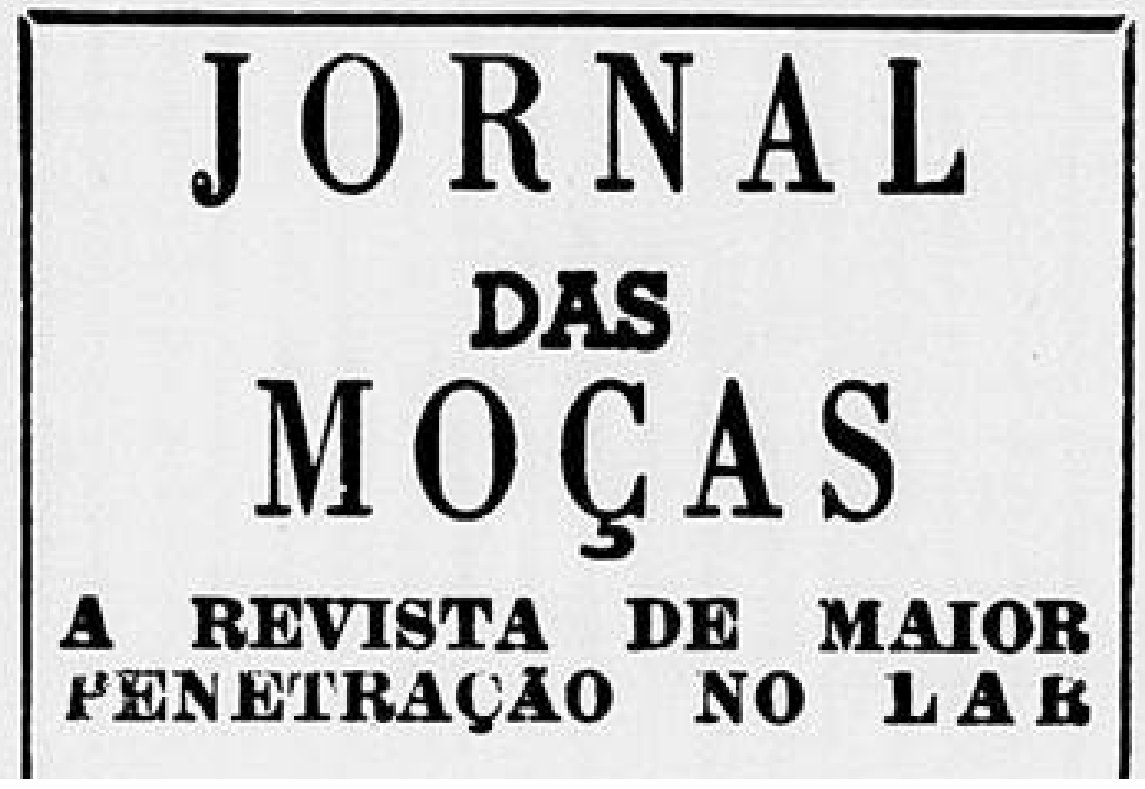

Figura 2 - Jornal das Moças, n. 2.220, 2 de janeiro de I958. Acervo:

Hemeroteca Digital da Fundação Biblioteca Nacional

A coluna chamada Um Broto por Semana, publicada entre I959 e I960, ilustrada com fotos, buscava a opinião do "broto" que a cada semana desfilava nas páginas da revista, trazendo perguntas sobre variados temas e sobre a vida pessoal da entrevistada. $\mathrm{O}$ "broto" era uma moça solteira, com idade variando entre I6 e 20 anos, frequentadora de um clube e participante dos concursos de beleza nele promovidos, que podia estar estudando ou trabalhando. No exemplar de I5 de outubro de I959 (n. 2.3I3, p. ), o broto entrevistado caracteriza a revista como "sadia e seleta que tem milhares de leitores de nossa alta sociedade".

Aponta Tânia Regina de Luca (2013, p. 459) que, nesse período, um aspecto comum 
às práticas desse tipo de revista feminina é o fato de organizarem os assuntos “a partir da perspectiva, opinião e gosto masculinos, uma vez que é esse o personagem que comanda todo o enredo".

A título de ilustração, indicando querer estreitar laços entre as leitoras e seus ídolos de cinema, como Elizabeth Taylor, a revista Jornal das Moças reproduzia, na edição 9 de julho de I959 (n. 2.299), a entrevista concedida a "uma grande revista norte-americana" pela atriz de "beleza serena" de Hollywood". Nessa entrevista, destaca "O decálogo da mulher ideal”, em que Liz Taylor dava conselhos de como as mulheres deveriam se portar no lar, na família e na sociedade para agradarem aos homens. No conjunto que compõe esses conselhos, entre o modo de vestir, o cozinhar bem e ser gentil, destacamos do decálogo o último deles, que recomendava "não fazer alarde da sua superioridade". De acordo com Batista (20I9, p. I2), a famosa atriz aconselhava:

Caso a mulher estivesse em condição de superioridade em relação ao homem, seja intelectual, econômica ou culturalmente, ela não deveria demonstrar isso, pois "nada afasta tanto um casal do que uma mulher independente, muito cônscia do seu próprio valor. Os homens gostam de ser superiores. Não custa deixá-los na ilusão".

Em meio a esses conselhos, propagandas, incentivo ao consumo, a articulista Flora Ferraz Veloso escreve a respeito de um espaço associativo de mulheres universitárias - a União Universitária Feminina.

\section{Ações da União Universitária Feminina nas linhas de Flora Ferraz Veloso}

A União Universitária Feminina (UUF), uma associação que congregava mulheres diplomadas e estudantes de ensino superior criada em I929, foi fundada pela engenheira Carmen Velasco Portinho, sua primeira presidente, ao lado de Bertha Lutz e outras mulheres. Portinho, em depoimento concedido a Geraldo Edson de Andrade em I998, esclarece sobre os objetivos dessa associação:

Apoiar as mulheres na carreira que escolhessem e defender os seus interesses nas profissões liberais; auxiliar por todos os meios as aulas das escolas superiores e conscientizar a mocidade feminina a adquirir preparo técnico superior; estimular o desenvolvimento da intelectualidade feminina, colaborar nas questões de alcance geral, que se relacionassem com o progresso dos povos. (PORTINHO, I999, p. 60).

No ano de fundação da UUF, ainda era exíguo o número de mulheres no ensino

6 Conforme definido por Pedro Butcher (2004, p. I6), o termo Hollywood é um "conceito flutuante [...] ele ora designa um estilo cinematográfico e marca genérica; ora qualquer obra de ficção produzida nos Estados Unidos; ora todo o complexo de produção e distribuição de filmes e programas de TV americanos, ou ainda o conjunto de companhias produtoras e distribuidoras de filmes". 
superior. De acordo com Heleieth Saffioti (2013, p. 307), "era reduzido o número de elementos do sexo feminino que, antes de I930, se deixaram absorver pelo segundo sistema de ensino, nele diplomando-se"?. Nesse sentido, justifica-se uma associação como essa, fundada por mulheres formadas ou estudantes de ensino superior, portanto profissionais liberais, reclamando o direito de ingressar efetivamente nesse espaço, nele permanecer e concluir seus estudos, e exercer a profissão, após se formarem, em pé de igualdade com os homens.

Considerando o início das atividades dessa associação, muitas conquistas feministas, como direitos civis, sociais e políticos, já haviam ocorrido anteriormente à década de I950, destacando-se o direito ao sufrágio universal e o aumento do número de mulheres nos espaços de ensino superior. Mas muito ainda havia para se conquistar, como mostra Flora Ferraz Veloso em suas linhas na revista Jornal das Moças.

A articulista, além de assinar a coluna fixa Sonhos e Sua Interpretação, e de seu nome aparecer no Expediente do periódico como colaboradora, escreveu matérias como "Personalidade feminina" e "A respeito da U.U.F." referentes a essa associação, que também foi mencionada na coluna.

Em "Outubro - Personalidade feminina”, publicada no exemplar n. 2.260, de 9 de outubro de I958, Flora Ferraz Veloso apresenta o debate travado pelas "senhoras diplomadas" sobre um tema bastante polêmico na época - a aposentadoria por tempo de serviço -, ocorrido em reunião realizada no Edifício Odeon ${ }^{8}$, sede da entidade localizada no centro da cidade do Rio de Janeiro. Entre os assuntos em pauta estava a Lei do Congresso, sancionada pelo presidente da República, que tornava a aposentadoria para os trabalhadores "compulsória aos 50 anos de idade". Nessa direção, uma participante da reunião propôs que a aposentadoria fosse diferenciada para a categoria de funcionários públicos, sendo 25 anos de serviço para as mulheres,

7 Cabe destacar que, embora o ensino superior estivesse presente no Brasil desde I808, com a vinda da família real, no aspecto legal, só foi dado o direito de as mulheres se inserirem nesse nível de ensino pelo Decreto n. n. 7.247, de I9 de abril de I879, que trata da Reforma do Ensino Primário e Secundário do Município da Corte e o Superior em todo o Império (BRASIL, I879), que ficou conhecida como Reforma Leôncio de Carvalho.

8 O Edifício Odeon, situado no centro da cidade do Rio de Janeiro, mais especificamente na Praça Cinelândia, foi oficialmente inaugurado em I926. Entretanto, desde o início do século XX, o Cine Odeon funciona no que hoje é o primeiro pavimento do prédio, sendo até os dias atuais um símbolo, visto que se na década de I920 existiam muitos cinemas de rua no seu entorno e atualmente ele é o único que restou (LUCENA, 20I6). Hoje, o Edifício Odeon é em um condomínio empresarial, abrigando vários serviços em suas salas comerciais.

9 Não foi identificada a lei objeto de discussão. 
permanecendo os 35 anos para os homens como estabelecido na lei federal ${ }^{\text {ro }}$. A "senhora diplomada" argumentava que a proposta era viável: encurtar o tempo no serviço público para aposentadoria feminina em postos mistos - onde havia a presença de homens e mulheres desempenhando a mesma função, tendo em vista que as professoras já gozavam desse direito.

A presidente da associação, dra. Zeia Pinho Rezende da Silva, ao afirmar que as mulheres não querem privilégios e sim igualdade e que o conceito de inferioridade física das mulheres já havia sido superado, considerava que reivindicar um tempo menor de aposentadoria em relação aos homens significaria um retrocesso para a luta emancipatória das mulheres. Defensoras dos direitos iguais entre homens e mulheres, as outras associadas consideraram que, se fosse concretizada a proposta, "poria por terra" todo o esforço, toda a "capacidade física e psíquica" das mulheres para se manterem "no mesmo pé de igualdade com os homens". Criticada, a proposta, por ainda corroborar a representação social das mulheres como "o sexo frágil", por elas tão combatida, acaba incorporando estruturas dominantes sociais, as quais inferiorizam as mulheres. Na percepção de Pierre Bourdieu (20I4, p. 46), o poder masculino sobre o feminino é exercido por meio do que ele denomina de violência simbólica, apontando que esse tipo de dominação acontece quando as mulheres são ainda meninas e aceitam valores instituídos pela sociedade, levando-as a achar natural a ordem social que lhes é imposta, através principalmente de agentes específicos, entre os quais os homens, "instituições, famílias, Igreja, Escola, Estado".

Outros temas que ocupavam a agenda da UUF eram o concurso do Banco do Brasil e a reforma do Código Civil. Considerando as diferentes expectativas da sociedade brasileira em relação aos papéis e comportamentos masculino e feminino, especialmente no que cabe ao exercício profissional, em "A respeito da U.U.F.", publicada em 6 de outubro de I960, a associação se pronuncia:

A Reforma do Código Civil, em relação aos artigos que restringem a capacidade legal das mulheres casadas, bem como modificações nas restrições que impedem as mulheres de ingressarem nos concursos do Banco do Brasil, têm sido constantemente focalizadas pela nossa União Universitária Feminina, com notável destaque. (VELOSO, Jornal das Moças, 6 out. I960, p. 8).

Vigia no país o Código Civil Brasileiro de I9I6, segundo o qual a mulher era obrigada a adotar o sobrenome do marido, tornando-se sua senhora, e, ao assumir a condição de esposa, deveria se submeter a sua autoridade e proteção, pois "o marido é o representante legal da família, e a esposa, sem plena capacidade civil, precisa da autorização do cônjuge para trabalhar e negociar" (PINSKY, 20I3, p. 486). A situação civil da mulher nos anos dourados apresentava-se restrita a dois homens: ao pai, enquanto era menor

Io Nos dias de hoje, sabemos que a mulher se aposenta mais cedo em relação ao homem, com tempo de exercício de atividades laborais menor. Em I3 de novembro 2019 foi aprovada a Emenda Constitucional n. I03, conhecida como Reforma da Previdência, que deliberou, entre outras coisas, o aumento do tempo de serviço e de contribuição para a aposentadoria, fixando para uso desse benefício como idade mínima 62 anos para as mulheres e 65 anos para os homens (BRASIL, 20I9). 
de idade, e ao marido, se casada fosse. Respingos do pensamento positivista do século XIX, a representação da mulher como inferior biologicamente, sexo frágil, dedicada ao lar, sendo o altar sua esperança de felicidade, e a maternidade, seu objetivo último (ALMEIDA, 2007). Isso justificava sua exclusão do espaço público masculino, apesar de algumas conquistas, como a possibilidade de cursar o ensino superior e votar.

O intercâmbio com outras instituições femininas é mais uma faceta da agremiação destacada pela articulista. Dois anos após a sua criação, a UUF filia-se à Federação Internacional de Mulheres Universitárias, sediada em Londres, capital da Inglaterra, ampliando horizontes na troca de ideias para diversas associações semelhantes ao redor do mundo, ultrapassando as fronteiras do Brasil, onde já estava organizada em estados como São Paulo, Rio de Janeiro, Sergipe e Bahia.

Flora ressalta à leitora da revista esse intercâmbio por proporcionar "às mulheres intelectuais" a oportunidade de se candidatarem às bolsas de estudos no exterior, as quais a União Universitária Feminina não só instituiu, como também distribuiu, tornando possível às mulheres fazer "pesquisas, investigações ou aperfeiçoamento". A edição do jornal Correio da Manhã de I959 publica a concessão da bolsa de estudos "Carmem Moura" a Creusa Moraes Chaves, estudante do quarto ano do curso de escultura da Escola Nacional de Artes e desenhista de botânica do Museu Nacional pelas mãos da engenheira Carmem Portinho, demonstrando assim que a primeira presidente da UUF ainda se faz presente.

No acervo do Arquivo Nacional, observa-se uma fotografia como memória imagética ilustrativa do aniversário de 30 anos da UUF. Visualiza-se, sentada à mesa, Bertha Lutz ao centro, ladeada por Carmem Portinho e outras associadas. Ainda nos faltam elementos suficientes para confirmar na imagem a presença de Flora Ferraz Veloso.

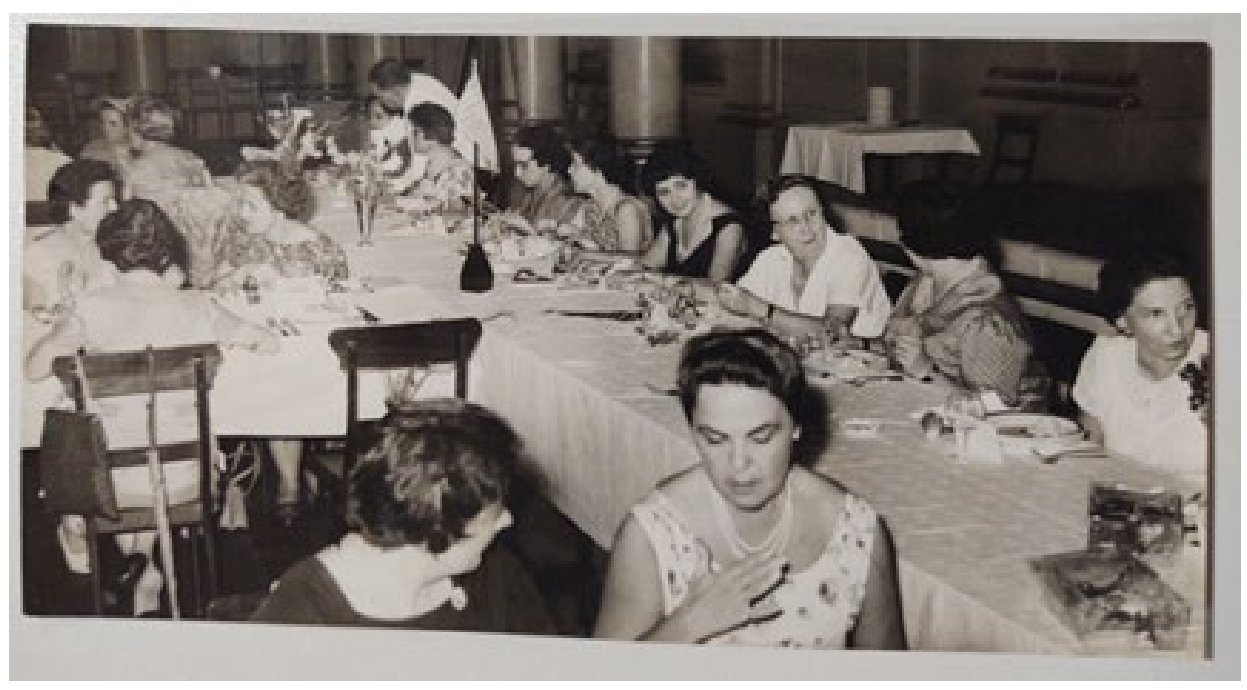

Figura 3 - Fundo Correio da Manhã - BR RJANRIO PH.o.FOT.6785. Ensino Guanabara (Associações Estudantis - União Universitária Feminina). Acervo: Arquivo Nacional 
No verso da imagem se encontra colado um recorte da edição de I4 de janeiro de I959, do jornal Correio da Manhã, com notícia sobre a comemoração de aniversário de 30 anos de fundação da União Universitária Feminina. Comunica que "ontem" a associação ofereceu almoço de confraternização comemorando seu aniversário de fundação. Na nota lê-se o nome das sócias fundadoras e outras mulheres que estiveram presentes na comemoração e na história da associação ${ }^{\mathrm{II}}$, além de diversas representantes de outras associações. sobre a intenção de se instituírem "bolsas de estudos tendo como patronos" os nomes de Carmem Moura e Iracy Doyle, "sócias falecidas", como forma de homenageá-las, no discurso proferido por Isabel do Prado, que será presidente da UUF, conforme identifica Flora na revista Jornal da Moças.

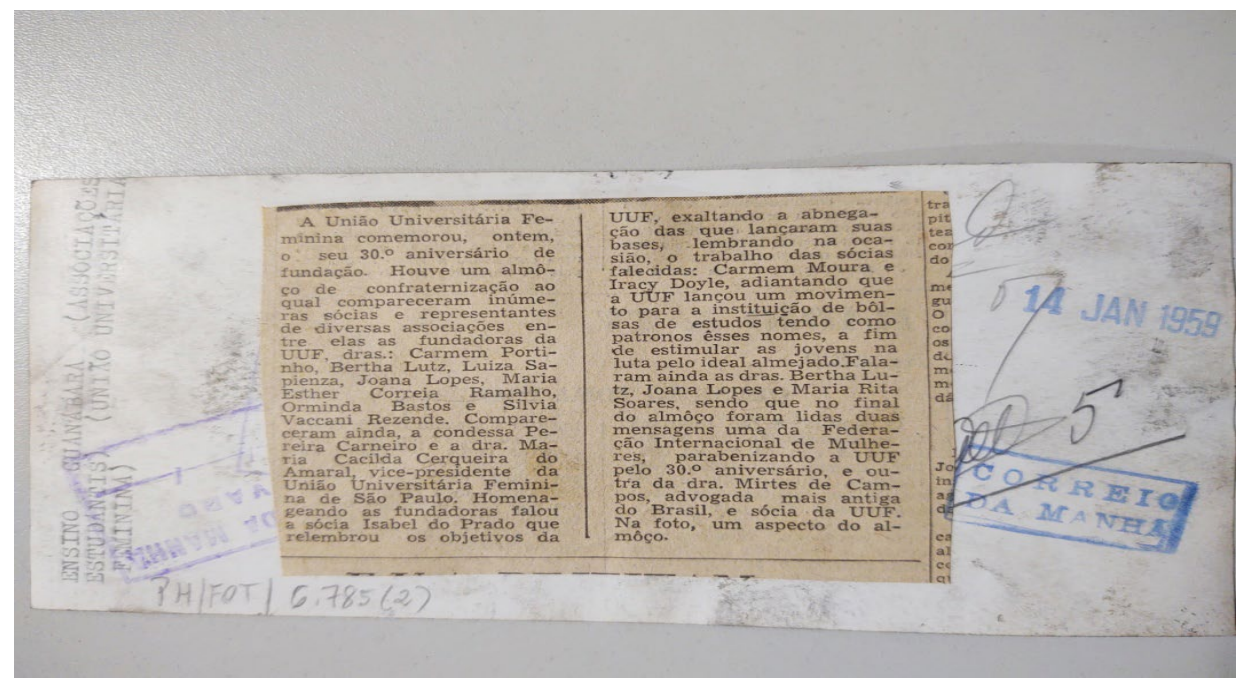

Figura 4- Recorte de jornal colado no verso da imagem. Fundo Correio da Manhã - BR RJANRIO PH.o.FOT.6785. Ensino Guanabara (Associações Estudantis - União Universitária Feminina). Acervo: Arquivo Nacional

Retornando à reportagem "A respeito da U.U.F.", publicada em 6 de outubro de I960, Flora trata Zeia Pinho como a "nossa presidente", e com isso denuncia ser membro da entidade. Talvez por ocupar esses dois espaços de atuação, como colaboradora da revista e membro da UUF, justifique a divulgação dessa entidade no periódico. Nessa luta por direitos iguais, Flora destaca a estrutura e a forma de atuação dessa associação de mulheres universitárias e, a fim de divulgá-la às leitoras da revista Jornal das Moças, esclarece o significado da sigla UUF. Dessa forma nos

II A reportagem cita a presença das sócias fundadoras da UUF: “dras.: Carmem Portinho, Bertha Lutz, Luiza Sapienza, Joana Lopes, Maria Esther Correia Ramalho, Orminda Bastos e Silvia Vaccani Rezende. Compareceram, ainda, a condessa Pereira Carneiro e a dra. Maria Cacilda Cerqueira do Amaral, vice-presidente da União Universitária Feminina de São Paulo”. Ainda aparecem outros nomes como o de Maria Rita Soares, que foi uma das oradoras, e de Mirtes de Campos, "advogada mais antiga do Brasil, e sócia da UUF” (Correio da Manhã, I4 jan.I959), mas não a primeira a se formar. 
brinda com dados importantes sobre a história da União Universitária Feminina. Segundo ela, "Fundada em I929, a U.U.F. tem como escopo coordenar os esforços das universitárias, no sentido de auxiliarem-se mutuamente, como o de defender os interesses femininos, na solução dos problemas relacionados com o progresso" (VELOSO, Jornal das Moças, 6 out. I960, p. 8).

A entidade foi criada no âmbito da Federação Brasileira pelo Progresso Feminino (FBPF), sendo consolidada durante o Segundo Congresso Internacional Feminista realizado em $\mathrm{I} \mathrm{II}^{\mathrm{I2}}$, onde teve participação ativa, identificando-se como uma "agremiação de classe, de alunas e formadas pelas escolas superiores para a defesa dos seus interesses e intensificação da atividade coletiva da mulher intelectual", conforme publicado na Revista da Semana, de 2 de julho de I932 (MARINHO, 20I6).

Entretanto, buscando cativar a atenção das leitoras sobre as vantagens de se associar à UUF, Flora "escorrega" sobre o papel instituído às mulheres na nossa sociedade, transitando entre o ontem e o hoje:

É hoje uma necessidade para a mulher que vai às urnas dar o seu voto não se encontrar divorciada dos assuntos que se encontram intrincados nas relações humanas, e que, de certo modo, causarão uma boa impressão no próprio lar, perante o seu marido e filhos. (VELOSO, Jornal das Moças, 6 out. I960, p. 7I).

Flora relembra a conquista histórica ocorrida em I932 - o direito ao voto feminino $^{\mathrm{I} 3}-$, evocando as mulheres a se informarem, cada vez mais, a respeito dos mais variados assuntos; ao mesmo tempo denuncia a concepção das ações das mulheres girarem em torno dos homens, do lar, dos filhos, da família. Nesse sentido, a ação de se filiar à UUF não somente causará "boa impressão no próprio lar, perante o seu marido e filhos”, como também as manterá a par dos mais variados assuntos pertinentes às relações humanas e não apenas à vida doméstica:

Se as mulheres, na sua maioria, demorassem um pouco o pensamento nas vantagens que aufeririam fazendo parte, como associadas, de tal corporação, veriam como os serviços domésticos - poderemos dizer assim - se tornariam menos pesados, menos embrutecedores, já que, tomando parte ativa nos diversos setores que compõem a vida social, recrearão, também, o espírito. (VELOSO, Jornal das Moças, 6 de out. I96o, p. 8).

Enaltecendo a "atual presidente", a dra. Isabel do Prado, a articulista anuncia

I2 Tendo à frente da organização do evento Bertha Lutz, presidente da FBPF, entre outras mulheres, nele a UUF teve participação ativa. Nesse Congresso havia theses discutindo se as mulheres no espaço de ensino superior deveriam estudar ao lado do homem (MARINHO, 20I6)).

I3 Conforme June Edith Hahner (2003, p. 29), o direito ao voto feminino era "uma bandeira já levantada no final do século XIX, após a instauração da República, mas negada pelo Congresso Constituinte, em I89I”. 
a representação da UUF na Federação Internacional de Mulheres Universitárias ${ }^{\mathrm{I}}$ enquanto líder dessa associação, destacando algumas ações promovidas pela União durante a gestão dessa consócia em prol da permanência das mulheres no ensino superior, promovendo chás, notadamente o Chá das Calouras, ofertado quando do ingresso no ensino superior, e o Chá da Vitória, ofertado quando do término do curso universitário, atividades realizadas pela entidade desde seus primórdios (PORTINHO, I999; REGIS, 20I2).

Como colunista da revista Jornal das Moças, no exemplar n. 2.34I, de 28 de abril de I960, Flora, em “Os sonhos e sua interpretação”, traz oportunamente a União Universitária Feminina. Entre o conjunto de eventos tradicionais proporcionados às associadas, além dos chás, havia também palestras acerca de questões específicas das mulheres. Nesse texto, Flora noticia a respeito da palestra "A menstruação e o psiquismo”, promovida pela associação, proferida pela dra. Isabel Melo, pesquisadora de Manguinhos ${ }^{\mathrm{I5}}$. A pesquisa realizada focava como tema a "variabilidade do humor feminino", tendo em vista as diversas fases do ciclo menstrual.

Considerando o "tema muito sugestivo e de interesse a todas as mulheres", e por tratar-se de uma coluna que se propõe a interpretar sonhos, da pesquisa da Dra. Isabel o que mais interessava era a afirmação de que essa excitação que precede as regras produz sonhos arrojados e conflituosos. A pesquisa conclui que "as mulheres delinquentes, quando cometem os seus crimes, estão na fase pré-menstrual, que lhes dá a energia necessária para esses impulsos” (VELOSO, Jornal das Moças, 28 abr. I96o, p. I5).

O destaque dado na nota de Flora à identificação da dra. Isabel Melo como pesquisadora de Manguinhos demonstrava às leitoras da revista a contribuição da UUF sobre temas tão relevantes a elas, certificado pelo conhecimento científico, sendo essa mais uma vantagem de se ligarem à associação.

\section{A advogada Flora Ferraz Veloso: a conquista do DIPLOMA OU O “BELO SEXO FRÁGIL” PERANTE O JÚRI}

A presença da UUF nas páginas da revista denota a necessidade de persistir, ainda na década de I950, uma entidade com esse perfil. Com isso, revisitamos o ensino superior na época e nele a presença feminina, focando nas formaturas do curso de direito.

Nos anos dourados, período compreendido como a “época que se estende de I945

14 A Federação Internacional de Mulheres Universitárias (FIMU) foi criada pela iniciativa de Virgínia Gildersleeve, reitora de uma das maiores escolas superiores femininas norte-americanas, a Barnard College, após a Primeira Guerra Mundial. Ao se juntar com a professora Carolina F. E. Spurgeon, da Universidade de Londres, criaram a Federação das Mulheres Universitárias, organizando sua primeira conferência em Londres, no verão de 1920. Daí em diante, começaram a englobar outras federações, nessa iniciativa de unir as estudantes universitárias ao redor do mundo (MEYER, s. d., p. 43).

I5 Assim denominado devido a sua localização geográfica. A história desse bairro se entrelaça ainda com a da Fundação Oswaldo Cruz. Manguinhos é um bairro localizado na Zona Norte do município do Rio de Janeiro, onde se encontra o Pavilhão Mourisco, prédio sede da Fundação (FIOCRUZ, s. d.). 
a I964" (PINSKY, 20I4, p. 9), o Brasil era um país subdesenvolvido, mas querendo sair de tal condição. Nessa perspectiva, a segunda metade da década de I950 será marcada irremediavelmente por JK - governo de I956 a I96I (BRASIL, 20I8). Nas palavras de Angela de Castro Gomes (2002, p. II), "nesses 'anos dourados' há sem dúvida uma grande figura: o presidente Juscelino Kubitschek”.

Acompanhado do slogan "50 anos em 5" e com um plano de metas "arrojado", Juscelino propagava alavancar a economia e tirar o Brasil do rol dos países agrário-exportadores. O Plano de Metas, por ele apresentado, era composto de um conjunto de 30 objetivos em diversos setores da economia, a serem alcançados ao longo de seu governo, sendo a meta 30 referente à intensificação da formação de pessoal técnico e à orientação da educação para o desenvolvimento ${ }^{\mathrm{T}}{ }^{6}$. No campo educacional, o momento é marcado pelo debate em prol da consolidação de uma primeira Lei de Diretrizes e Bases da Educação Nacional (LDBEN), iniciado em I948 e retomado na segunda metade da década de I950 (XAVIER, I990). Essa lei seria instituída sob o $\mathrm{n}^{\circ} 4.024$, em I96I, encerrando esse ciclo de debates que, entre outras coisas, também definiu parâmetros referentes ao ensino superior. Entretanto, no ano de instituição da primeira LDBEN, a associação de mulheres universitárias atualiza seus estatutos passando a se chamar Associação Brasileira de Mulheres Universitárias (ABMU) (SOIHET, I974).

O momento político, econômico e social de euforia nacional-desenvolvimentista, expresso na figura do presidente Juscelino Kubitschek, buscando tirar o Brasil da condição de país subdesenvolvido, gerou uma sensação de felicidade e de estabilidade financeira, fazendo com que a população acreditasse ser possível melhorar de vida. O ensino superior se inseriu nessa aura de "sonho", como uma porta se abrindo para mulheres e homens ascenderem socialmente. Nos anos dourados, de I945 a I964, ocorreu a expansão do ensino superior no país, tendo o número de universidades crescido de 5 para 37. No caso das instituições isoladas, o aumento foi de 293 para 564 (MENDONÇA, 2000).

Em termos normativos, a Lei Orgânica do Ensino Secundário, instituída pelo Decreto-Lei n. 4.244, de 9 de abril de I942, regulamentava que aos alunos que concluíssem o curso clássico ou o científico mediante exames seria assegurado o direito de ingressar em qualquer curso do ensino superior, ressalvadas as exigências peculiares à matrícula. Nesse mesmo decreto-lei, percebemos regulamentação específica voltada ao público feminino estipulada no artigo 25. "Serão observadas, no ensino secundário feminino, as seguintes prescrições especiais":

I6 Embora não tenha sido incluída inicialmente como um dos itens do Plano, a construção de Brasília "representava um compromisso de campanha e podia ser considerada uma meta-símbolo" (FARO; SILVA, 2002, p. 89), tornando-se então, a capital federal do Brasil. O Plano de Metas mencionava cinco setores básicos da economia: 93\% dos recursos alocados fora para setores de energia, transporte e indústrias de base. Esse percentual demonstra que os recursos destinados aos outros dois setores incluídos no plano, alimentação e educação, não mereceram o mesmo tratamento dos primeiros (SILVA, s. d.). 
I. É recomendável que a educação secundária das mulheres se faça em estabelecimentos de ensino de exclusiva frequência feminina.

2. Nos estabelecimentos de ensino secundário frequentados por homens e mulheres, será a educação destas ministrada em classes exclusivamente femininas. [...]

3. Incluir-se-á, na terceira e na quarta série do curso ginasial e em todas as séries dos cursos clássico e científico, a disciplina de economia doméstica.

4. A orientação metodológica dos programas terá em mira a natureza da personalidade feminina e bem assim a missão da mulher dentro do lar. (BRASIL, I942).

Por outro lado, instituída pelo Decreto-Lei n. 8.530, de 2 de janeiro de I946, a Lei Orgânica do Ensino Normal, em seu artigo $6^{\circ}$, estabelecia que: "Aos alunos que concluírem o segundo ciclo de ensino normal, será assegurado o direito de ingresso em cursos da faculdade de filosofia, ressalvadas, em cada caso, as exigências peculiares à matrícula" (BRASIL, I946). Desse modo, uma moça menor de 2I anos deveria concluir o curso científico ou o clássico e, na sequência, realizar o exame para ingressar no ensino superior.

Mesmo frente a essas limitações legislativas, a articulista Flora Ferraz Veloso da revista Jornal das Moças concluiu o curso de direito e divulgou a entidade da qual era militante, a União Universitária Feminina. Sobre a vida dela pouco ainda sabemos, mas podemos afirmar que, além de ser articulista desse periódico, militante filiada à UUF, também era advogada. Em I950, fez sua estreia no Tribunal do Júri, motivo de notícia intitulada "Acusada de ministrar vidro moído ao marido foi absolvida por unanimidade", publicada no exemplar n. I7.704 do jornal Correio da Manhã de 2 de dezembro do mesmo ano.

A discussão trazida por Flora sobre a entidade e sua atuação como advogada não apaga das páginas da revista a representação do feminino como "o belo sexo", não se furtando o periódico a publicar matérias a respeito de formaturas referentes ao curso de direito. Em janeiro de I956, no exemplar n. 2.0I9, em "Uma homenagem aos novos advogados", o glamour da formatura era demonstrado não apenas pelas roupas de gala e a beca oficial usada pelos novos formandos, mas também por contar com a presença de personalidades ilustres como, por exemplo, o ex-presidente da república Eurico Gaspar Dutra.

Considerando os entraves legais daquele momento histórico em relação ao ingresso de mulheres no ensino superior, a presença de formandas no curso de direito significava a possibilidade de novas discussões a respeito de aspectos jurídicos limitadores da emancipação feminina.

As poucas formandas da turma de I956 do curso de direito vislumbravam um caminho para alteração das normas legais restritivas à sua condição feminina. Demonstraram que a situação de desigualdade entre mulheres e homens não é definitiva, que o lugar do "belo sexo" também é no espaço universitário e, quando formadas, é possível estar atuando perante o júri, como fez nossa protagonista Flora Ferraz Veloso, articulista da revista Jornal das Moças, advogada e militante da União Universitária Feminina. 


\section{CONSIDERAÇõES FINAIS}

Sabemos que o espaço do ensino superior ainda é para uns poucos e que as desigualdades educacionais continuam, não apenas na perspectiva de gênero. Se hoje, em números absolutos, as mulheres já são maioria nos bancos universitários, isso não significa igualdade se consideradas outras variáveis como: raça/cor, idade, nível socioeconômico, cursos que realizam, além das múltiplas jornadas cotidianas enfrentadas pelas mulheres estudantes, especialmente das classes menos abastadas.

Porém, não podemos desconsiderar historicamente a atuação da UUF e suas associadas mulheres privilegiadas - o fato de serem "senhoras diplomadas" já as coloca nessa posição social. A entidade, a seu modo, contribuiu para o ingresso e a permanência de mulheres no ensino superior, assim como a liberdade do exercício da profissão depois de formadas, na busca do direito à cidadania negado às mulheres, entre outras pautas. Trata-se de uma agremiação que reunia em seu interior desde jovens moças estudantes a mulheres diplomadas no ensino superior, exercendo a profissão por elas escolhida, como o foi o caso de Flora Ferraz Veloso, uma de suas consócias, que militou através das linhas da revista Jornal das Moças.

Como vimos, barreiras legais se colocavam às mulheres no tempo de Flora, e sua atuação nas páginas da revista Jornal das Moças se configurou como a de uma intelectual mediadora (GOMES; HANSEN, 20I6), cumprindo seu papel de militante na causa que defendia.

Folhear as páginas desse periódico nos levou, através das linhas da articulista, à advogada Flora Ferraz Veloso, à rede de relações da União Universitária Feminina, à filiação à Federação Internacional de Mulheres Universitárias, e ainda nos brindou com a apresentação e identificação de algumas mulheres militantes associadas ou colaboradoras, como, além da própria Flora, as presidentes da entidade, Zeia Pinto Rezende da Silva e Isabel do Prado, e a pesquisadora de Manguinhos Isabel Melo, sendo que a elas dedicaremos outros trabalhados. Destaca-se a presença de Flora Ferraz Veloso na e para essa instituição ao se expressar nas páginas da revista Jornal da Moças enquanto associada, militante e divulgadora de suas ações em prol do "progresso" feminino. 
NAILDA MARINHO DA COSTA é professora titular do Departamento de Fundamentos da Educação da Universidade Federal do Estado do Rio de Janeiro (EE/UniRio), coordenadora do Curso de Mestrado em Educação do Programa de Pós-Graduação em Educação (PPGEdu/UniRio) e do Núcleo de Estudos e Pesquisas em História da Educação Brasileira (NEPHEB/UniRio).

nailda.costa@unirio.br

http://orcid.org/oooo-0002-9348-9778

PRISCILA DIEGUEZ é doutoranda no Programa de Pós-Graduação em Educação da Universidade Federal do Estado do Rio de Janeiro (PPGEdu/UniRio) e pesquisadora do Núcleo de Estudos e Pesquisas em História da Educação Brasileira (NEPHEB/UniRio). prisciladieguez@hotmail.com https://orcid.org/oooo-0003-26I7-33I6

\section{REFERÊNCIAS}

ACUSADA de ministrar vidro moído ao marido foi absolvida por unanimidade. Correio da Manhã, n. I7.704, 2 de dezembro de I950, p. 3.

ALBUQUERQUE, Dálete C. S. Heitor de. O discurso estabelecido na revista Jornal das Moças. In: SIMPÓSIO NACIONAL DE HISTÓRIA CULTURAL, 7., Escritas, Circulação, Leituras e Recepções. Universidade de São Paulo, Io e I4 de novembro de 20I4. Anais... Disponível em: http://gthistoriacultural.com.br/ VIIsimposio/conf-D.php Acesso em: I5 maio 2020.

ALMEIDA, Jane Soares de. Ler as letras: por que educar meninas e mulheres?. São Paulo: Universidade Metodista de São Paulo; Autores Associados, 2007.

BOLSA de estudos oferecida pela UUF. Correio da Manhã, n. I9.997, I4 de maio de I958, p. 3.

BOURDIEU, Pierre. A dominação masculina. I2. ed. Rio de Janeiro: Bertrand Brasil, 20I4.

BRASIL. Decreto-lei n. 7.247, de I9 de abril de I879. Reforma o ensino primário e secundário no município da Corte e o superior em todo o Império. Legislação informatizada. Publicação original. Disponível em: https:/www2.camara.leg.br/legin/fed/decret/I824-I899/decreto-7247-I9-abril-I879-547933-publicacaooriginal-62862-pe.html. Acesso em: I8 maio 2020.

BRASIL. Lei n. 3.071, de I ${ }^{0}$ de janeiro de I9I6. Código Civil dos Estados Unidos do Brasil. Disponível em: http://www.planalto.gov.br/ccivil_03/leis/L307Iimpressao.htm. Acesso em: I8 maio 2020.

BRASIL. Decreto-lei n. 4.244, de 9 de abril de I942. Lei Orgânica do Ensino Secundário. Legislação informatizada. Publicação original. Disponível em: http://www2.camara.leg.br/legin/fed/declei/I940-I949/ decreto-lei-4244-9-abril-I942-4I4I55-publicacaooriginal-I-pe.html. Acesso em: I8 maio 2020. 
BRASIL. Decreto-lei n. 8.530, de 2 de janeiro de 1946. Lei Orgânica do Ensino Normal. Legislação informatizada. Publicação original. Disponível em: https://www2.camara.leg.br/legin/fed/declei/I940-I949/ decreto-lei-8530-2-janeiro-I946-458443-publicacaooriginal-I-pe.html. Acesso em: I8 maio 2020.

BRASIL. Presidência da República. Planalto. Galeria de presidentes. Atualizado em 28 fev. 20I8. Disponível em: https://www.gov.br/planalto/pt-br/conheca-a-presidencia/acervo/galeria-de-presidentes?b_start:int=20. Acesso em: 26 abr. 2020.

BRASIL. Senado Federal. Secretaria-Geral da Mesa. Secretaria de Informação Legislativa. Emenda Constitucional n. I3. Altera o sistema de previdência social e estabelece regras de transição e disposições transitórias. Brasília, I2 de novembro de 20I9. Disponível em: https://legis.senado.leg.br/ norma/3I727296/publicacao/3I727643. Acesso em: I8 maio 2020.

BUTCHER, Pedro. A reinvenção de Hollywood: cinema americano e produção de subjetividade nas sociedades de controle. Contemporânea, v. 2, n. 2, edição 3, 2004, p. I4-26. Disponível em: https://www.e-publicacoes.ueri.br/index.php/contemporanea/article/view/23I5/165I5. Acesso em: 55 maio 2020.

CHARTIER, Roger. Textos, impressão, leituras. In: HUNT, Lynn. A nova história cultural. Trad. Jefferson Luis Camargo. São Paulo: Martins Fontes, I992.

CORREIO da Manhã, n. 20.I85, I4 de janeiro de I959, p. II.

CPDOC/FGV - Centro de Pesquisa e Documentação de História Contemporânea do Brasil. Fundação Getulio Vargas. Disponível em: www.cpdoc.fgv.br. Acesso em: I5 maio 2020.

BATISTA, Priscila Dieguez Alves. Lugar de mulher é na sala de aula ou na cozinha? A inserção feminina no ensino superior durante os anos dourados: um olhar através do Jornal das Moças. Dissertação (Mestrado em Educação). Programa de Pós-graduação em Educação, Universidade Federal do Estado do Rio de Janeiro, 20I9.

FARO, Clovis de; SILVA, Salomão L. Quadros da. A década de I950 e o Programa de Metas. In: GOMES, Angela de Castro (org.). O Brasil de JK. 2. ed. Rio de Janeiro: Editora FGC, 2002, p. 67-IO6.

FIOCRUZ - Fundação Oswaldo Cruz. História. s. d. Disponível em: https://portal.fiocruz.br/historia. Acesso em: 25 mar. 2020.

GOMES, Angela de Castro (org.). O Brasil de JK. 2. ed. Rio de Janeiro: Editora FGC, 2002.

GOMES, Angela de Castro; HANSEN, Patricia Santos (org.). Intelectuais mediadores: práticas culturais e ação política. Rio de Janeiro: Civilização Brasileira, 2016.

GONÇALVES, Andréa Lisly. História er gênero. Belo Horizonte: Autêntica, 2006.

HEMEROTECA Digital Brasileira da Fundação Biblioteca Nacional. Disponível em: https://bndigital. bn.gov.br/hemeroteca-digital/. Acesso em: I5 maio 2020.

HAHNER, June Edith. Emancipação do sexo feminino: a luta pelos direitos da mulher no Brasil, I850- I940. Tradução de Eliane Lisboa; apresentação de Joana Maria Pedro. Florianópolis: Ed. Mulheres; Santa Cruz do Sul: Edunisc, 2003.

JORNAL DAS MOÇAS. Disponível em: http://bndigital.bn.br/acervo-digital/jornal-mocas/IIO3I.

LUCA, Tania Regina de. Mulheres em revista. In: PINSKY, Carla Bassanezi; PEDRO, Joana Maria (org.). Nova história das mulheres no Brasil. I. ed. São Paulo: Contexto, 2013.

LUCENA, Felipe. História do Cine Odeon. 2 de junho de 20I6. Disponível em: https://diariodorio.com/ histria-do-cine-odeon. Acesso em: I5 maio 2020.

MAIS uma vitória conquistada. Jornal das Moças, n. 2.I70, I7 de janeiro de I957, p. I2-I3.

MARINHO, Nailda. A engenheira militante feminista Carmen Portinho: a atuação na União Universitária Feminina. In: GASPARELLO, Arlette Medeiros; VILLELA, Heloisa de Oliveira Santos (org.). Educação na história: intelectuais, saberes e ações instituintes. Rio de Janeiro: Mauad X, 2016, p. 2I5-232.

MARTINS, Ana Luiza; LUCA, Tania Regina de. Imprensa e cidade. São Paulo: Editora Unesp, 2006. 


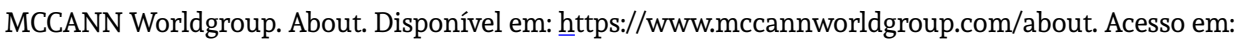
II maio 2020.

MENDONÇA, Ana Waleska P. C. A universidade no Brasil. Revista Brasileira de Educação (online), n. I4, 2000, p. I3I-I50. Disponível em: http://www.scielo.br/pdf/rbedu/nI4/nI4a08.pdf. Acesso em: I5 maio 2020.

MEYER, Agnes E. Virgínia Gildersleeve. U.S.A. - uma revista americana, v. 2, n. 7, Secretaria das Informações de Guerra dos EUA, Universidade de Indiana, s. d., p. 42-45. Digitalizado 4 fev. 20I9. Googlebooks. Disponível em: https://bit.ly/3wzvhh8. Acesso em: 20 maio 2020.

O DECÁLOGO da mulher ideal. Jornal das Moças, n. 2.299, 9 de julho de I959, p. Io.

PINSKY, Carla Bassanezi. A era dos modelos rígidos. In: PINSKY, Carla Bassanezi; PEDRO, Joana M. (org.). Nova história das mulheres no Brasil. I. ed. São Paulo: Contexto, 2013, p. 469-5I2.

PINSKY, Carla Bassanezi. Mulheres dos anos dourados. São Paulo: Contexto, 20I4.

PORTINHO, Carmem. Por toda a minha vida/Carmem Portinho. Depoimento a Geraldo Edson de Andrade. Rio de Janeiro: Eduerj, I999.

REGIS, Caren Victorino. A presença feminina na Casa do Estudante do Brasil (I93I-I95I): a atuação da União Universitária Feminina. Dissertação (Mestrado em Educação). Universidade Federal do Estado do Rio de Janeiro, 2012.

SAFFIOTI, Heleieth Iara Bongiovani. A mulher na sociedade de classes: mito e realidade. 3. ed. São Paulo: Expressão Popular, 2013.

SANTOS, Liana Pereira Borba dos. Mulheres e revistas: a dimensão educativa dos periódicos femininos Jornal das Moças, Querida e Vida Doméstica nos anos I950. Dissertação (Mestrado). Faculdade de Educação. Universidade do Estado do Rio de Janeiro, $20 I I$.

SASAKI, Silvia. Tessituras sociais: alinhavos entre costumes e modelos vigentes através do Jornal das Moças (I948-I968). Dissertação (Mestrado). Programa de Pós-Graduação em História. Centro de Ciências Humanas e da Educação, Universidade do Estado de Santa Catarina, Florianópolis, $20 I I$.

SAVIANI, Demerval. Entrevista com Demerval Saviani realizada por Dalton José Alves e Nailda Marinho da Costa Bonato, em Campinas, em Io de janeiro de 2006. Acervo - Revista do Arquivo Nacional, Rio de Janeiro, v. I8, n. I-2, jan.-dez. 2005, p. 5-I4. Disponível em: http://revista.arquivonacional.gov.br/ index.php/revistaacervo/article/view/I82/I82. Acesso em: I4 abr. 2019.

SCOTT, Joan. Gênero: uma categoria útil de análise histórica. Educação e Realidade. Porto Alegre, v. 20, n. 2, jul.-dez. I995, p. 7I-99.

SILVA, Suely Braga da. O Brasil de JK - 50 anos em 5: o Plano de Metas. s. d. CPDOC/FGV. Disponível em: https://cpdoc.fgv.br/producao/dossies/JK/artigos/Economia/PlanodeMetas. Acesso em: $\amalg$ maio 2020.

SOARES, Diogo dos Santos; SILVA, Ursula Rosa da. O Jornal das Moças: uma narrativa ilustrada das mulheres de 30 a 50 \& sua passagem por Pelotas nas décadas. UFPel. In: SEMINÁRIO DE HISTÓRIA DA ARTE, I2. Anais..., 20I3. Disponível em: https://periodicos.ufpel.edu.br/ojs2/index.php/Arte/article/ view/3013/2594. Acesso em: 20 maio 2020.

SOARES, Marina Juliana de Oliveira. Mary Montagu e a inoculação da varíola na Inglaterra no século XVIII. Khronos, Revista de História da Ciência, n. 5, maio 20I8, p. 35-46. Disponível em: https://www. revistas.usp.br/khronos/article/view/I42399. Acesso em: 20 maio 2020.

SOIHET, Rachel. Bertha Lutz e a ascensão social da mulher, I9I9-I937. Dissertação submetida ao Instituto de Ciências Humanas e Filosofia da Universidade Federal Fluminense, I974.

UMA HOMENAGEM aos novos advogados. Jornal das Moças, n. 2.0I9, 26 de janeiro de I956, p. 8-9.

VELOSO, Flora Ferraz. Outubro - Personalidade feminina. Jornal das Moças, n. 2.260, 9 de outubro de I958, p. I6. 
VELOSO, Flora Ferraz. A respeito da U.U.F. Jornal das Moças, n. 2.364, 28 de abril de I96o, p. I4-I5.

VELOSO, Flora Ferraz. Os sonhos e sua interpretação. Jornal das Moças, n. 2.34I, 6 de outubro de I96o, p. 8, p. 7I.

XAVIER, Maria Elisabete Sampaio Prado. Capitalismo e escola no Brasil: a constituição do liberalismo em ideologia educacional e as reformas do ensino (I93I-I96I). Campinas: Papirus, I990. 